\title{
Teknologi Penangkapan Rajungan (Portunus pelagicus spp.) Ramah Lingkungan dengan Bubu Kubah di Kabupaten Aceh Barat Provinsi Aceh
}

\section{Eco-friendly Fishing Technology for Blue Swimming Crab (Portunus pelagicus spp) with Traps in West Aceh District Aceh Province}

\author{
Hafinuddin ${ }^{1}$, Edwarsyah² \\ 1 Program Studi Perikanan, Fakultas Perikanan dan IImu Kelautan, Universitas Teuku Umar, Meulaboh, \\ Indonesia; ${ }^{2}$ Program Studi Manajemen Sumberdaya Akuatik, Fakultas Perikanan dan Ilmu Kelautan, \\ Universitas Teuku Umar, Meulaboh, Indonesia \\ * Korepondensi: hafinuddin@utu.ac.id
}

\begin{abstract}
ABSTRAK
Nelayan Kabupaten Aceh Barat masih menggunakan alat tangkap yang tidak ramah lingkungan yaitu mini trawl untuk penangkapan rajungan (portunus pelagicus spp.), sehingga akan berdampak kepada rusaknya ekosistem laut dan musnahnya sumberdaya ikan yaitu rajungan. Oleh karena itu, diperlukan alternatif teknologi penangkapan rajungan yang ramah lingkungan yang mampu menggantikan alat tangkap mini trawl untuk penangkapan rajungan dan menjadikan usaha penangkapan rajungan sebagai usaha penangkapan andalan di Kabupaten Aceh Barat melalui desa pilot project yaitu Desa Ujong Baroh. Kegiatan pengabdian kepada masyarakat ini dilaksanakan dalam program Ipteks bagi Masyarakat (IbM). Pendekatan yang telah dilakukan kepada mitra mulai dari Februari-Agustus 2017 adalah edukasi, pelatihan dan pedampingan. Program Ipteks bagi Masyarakat (IbM) yang telah dilakukan diharapkan mampu meningkatkan keterampilan dan kemampuan manajerial usaha penangkapan serta peningkatan taraf ekonomi masyarakat pesisir.

Kata Kunci: bubu kubah, Portunus pelagicus spp., pengabdian kepada masyarakat
\end{abstract}

ABSTRACT
Fishermen of West Aceh District is still using a tool of unfriendly for environment namely mini trawl for blue swimming crab (Portunus pelagicus spp) fishing, so that it will impact the ecosytem of the sea and the damage to the fish resources such as blue swimming crab. For that reason, there needs to be an alternative of eco-friendly fishing technology to catching blue swimming crab and replace fishing gear unfriendly for environment i.e. mini trawl and exposing the blue swimming crab fishing is as main activity in West Aceh District where Ujong Baroh Village as pilot projetc location for this activity. The community service program has carried out with IbM activity (Ipteks bagi Masyarakat). The activity was done on February - Agustus 2017, where education, practice and accomponiment was used as methods. IbM program is expected to increase skill and business managerial as well as improving the economic situation of the coastal communities.

Key word: traps, blue swimming crab, Portunus pelagicus spp, IbM

\section{PENDAHULUAN \\ Latar Belakang}

Penangkapan ikan ramah lingkungan merupakan hasil perilaku penangkapan ikan dengan menggunakan jenis alat penangkap ikan dengan metode tertentu pada daerah penangkapan ikan diluar habitat secara selektif tanpa merusak atau tidak mengganggu keseimbangan sumberdaya ikan dan lingkungan, tidak terjadi konflik sehingga menjamin keberlangsungan usaha penangkapan ikan (Zarochman, 2015).

Perangkap (traps) atau bubu kubah merupakan teknologi penangkapan ikan yang ramah lingkungan serta menghasilkan hasil tangkapan target yaitu rajungan 3 kali lebih besar 
dibandingkan alat tangkap bubu kotak (Zarohman, 2015). Selama ini, nelayan Kabupaten Aceh Barat masih menggunakan mini trawl untuk penangkapan rajungan (Gambar 1).

Penangkapan ikan dengan mini trawl merupakan penangkapan ikan yang tidak ramah lingkungan dan telah dilarang melalui Permen KP No 2 Tahun 2015. Pelarangan suatu alat tangkap tentu akan menjadi permasalahan baru bagi nelayan jika mereka tidak dibekali dengan informasi teknologi penangkapan yang mampu menggantikan alat tangkap yang telah dilarang yang berakibat nelayan tersebut akan kehilangan usaha penangkapan ikan.

Kondisi harga rajungan yang relatif bagus yaitu berkisar antara $\mathrm{Rp} 60.000-70.000$ per kg sehingga prospek usaha penangkapan rajungan dengan bubu kubah menjadi pilihan yang sangat baik. Usaha penangkapan yang menguntungkan dan tetap terjaganya sumberdaya ikan (SDI) serta ekosistem laut merupakan kebutuhan yang mendasar saat ini di zona potensi penangkapan ikan (ZPPI) Kabupaten Aceh Barat - ditengah ancaman penggunaaan alat tangkap yang tidak ramah lingkungan seperti pukat mini trawl.

Pengadopsian teknologi penangkapan bubu kubah untuk rajungan adalah sebuah alternatif usaha yang potensial bagi nelayan pukat mini trawl. Kegiatan pengabdian kepada masyarakat ini dilakukan kepada mitra kelompok nelayan perintis. Kelompok nelayan perintis adalah kelompok nelayan yang berada di Desa Ujong Baroh Kecamatan Johan Pahlawan. Mitra kelompok nelayan yang dipilih merupakan nelayan/individu yang selama ini melakukan penangkapan rajungan dengan menggunakan pukat mini trawl.

\section{Masalah}

Penggunaan alat tangkap mini trawl untuk penangkapan rajungan yang dilakukan oleh mitra kelompok nelayan perintis, menyebabkan habitat dan sumberdaya ikan (rajungan) terancam punah. Ukuran rajungan yang tidak layak tangkap dan banyaknya hasil tangkapan sampingan (by catch) seharusnya usaha penangkapan ini sudah ditinggalkan. Selain permasalahan alat penangkapan, terdapat pula permasalahan permodalan dan manajemen usaha.

Beberapa permasalahan mitra/nelayan mini trawl yang dari segi alat penangkapan yaitu antara lain: (1) alat tangkap trawl mengakibatkan jumlah hasil tangkapan target relatif kecil dan banyaknya hasil tangkapan non-target, (2) kurangnya informasi alat tangkap tepat guna dan ekonomis serta ramah lingkungan untuk penangkapan rajungan, (3) masih sangat bergantungnya mitra/nelayan pada alat tangkap trawl sehingga sumberdaya ikan dan ekosistem laut akan hancur bahkan punah.

\section{METODE}

Metode yang telah digunakan dalam pengabdian kepada masyarakat nelayan mini trawl adalah sebagai berikut:

1) Pendampingan dan sosialisasi mengenai alat tangkap bubu kubah kepada anggota kelompok nelayan mitra. Kegiatan dilakukan dalam bentuk diskusi interaktif langsung kepada anggota kelompok nelayan mitra dengan tujuan membuka wawasan mengenai alat tangkap bubu kubah;

2) Pelatihan pembuatan bubu lipat meliputi:

a. Penyiapan alat dan bahan pembuatan bubu kubah;

b. Pembuatan bubu kubah;

3) Penentuan daerah penangkapan ikan 
a. Penentuan daerah penangkapan yang tepat dan

b. Pengoperasian alat tangkap bubu kubah.

Untuk pemberdayaan kelompok nelayan mitra, seluruh kegiatan penerapan alat tangkap melibatkan langsung anggota kelompok dalam pelaksanaan program seperti penyiapan alat dan bahan yang digunakan, teknik pembuatan alat tangkap, proses penentuan daerah tangkapan (fishing ground) dan teknik pengoperasian alat tangkap. Untuk penerapan dan meningkatkan keterampilan dalam pembuatan alat tangkap perangkap (traps) lipat, maka anggota kelompok nelayan mitra akan dibagi lagi menjadi 3 (tiga) kelompok kecil sehingga seluruh program penerapan dan pelatihan yang ditawarkan mampu diserap dengan baik oleh anggota kelompok nelayan mitra. Sedangkan analisis kelayakan usaha dilakukan dengan pedampingan yang berkala dan berkesinambungan.

\section{HASIL DAN PEMBAHASAN}

\section{Keadaan Umum Daerah Pengabdian kepada Masyarakat}

Kabupaten Aceh Barat memiliki luas 2.927,95 $\mathrm{Km}^{2}$ yang terdiri dari 12 kecamatan, 33 mukim dan 322 gampong. Wilayah Kabupaten Aceh Barat secara

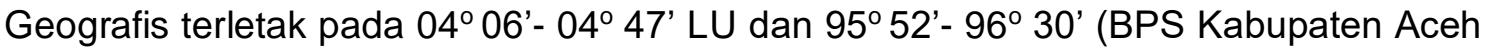
Barat, 2016).

Lokasi pengabdian kepada masyarakat adalah di Desa Ujong Baroh Kecamatan Johan Pahlawan Kabupaten Aceh Barat. Peta lokasi pengabdian dapat dilihat pada Gambar 2.

\section{Sosialisasi Penangkapan Ikan Ramah Lingkungan}

Kegiatan sosialisai yang telah dilakukan kepada nelayan di Desa Ujong Baroh Kabupaten Aceh Barat adalah dalam bentuk diskusi interaktif langsung kepada anggota kelompok nelayan mitra. Kegiatan ini bertujuan membuka wawasan dan menambah pengetahuan mengenai pentingnya penangkapan ikan yang berkelanjutan (sustainable of fisheries). Pada pertemuan ini juga telah disampaikan tentang dampak positif dan menguntungkan penangkapan rajungan menggunakan bubub kubah. Kegiatan dilakukan dalam 2 kali pertemuan.

\section{Pelatihan Pembuatan Bubu Kubah}

Kegiatan ini dilakukan sebanyak 7 kali pertemuan. Kegiatan ini merupakan kegiatan transfer pengetahuan teknologi yang mencakup dalam tiga kegiatan:

\section{Pembuatan bubu kubah}

Pembuatan bubu kubah dimulai dengan persiapan bahan dan alat. Adapun alat dan bahan yang digunakan adalah sebagai berikut:

1) Alat

Alat yang digunakan dalam kegiatan pembuatan bubu kubah terdiri atas pemotong kawat, pembengkok besi, tang, gergaji besi, penggaris, coban, sarung tangan, mal bubu kubah, gunting dan cutteripisau.

2) Bahan

Bahan yang digunakan dalam kegiatan pembuatan bubu kubah adalah beton eser, webbing polyethylene (PE), tali PE dan Stainlessteel. Untuk lebih jelas bahan 
yang digunakan dalam kegiatan pengabdian kepada masyarakat dapat dilihat pada Tabel 1.

Bubu kubah yang dibuat atau ditransfer ke mitra adalah bubu kubah dengan kontruksi tipe pintu samping dengan tinggi $18.2 \mathrm{~cm}$ dan diameter alas bubu $48 \mathrm{~cm}$, berkerangka dari bahan kawat lengkung, berdinding webbing PE 1.25 inci dan dapat dilipat dan memiliki 2 pintu samping (Gambar 3).

\section{Pengoperasian Bubu Kubah}

Pengoperasian alat tangkap perangkap bubu kubah diujicobakan selama 5 hari dengan menggunakan 30 bubu kubah. Tahapan pengoperasian bubu kubah adalah 1) tahap persiapan; 2) penentuan daerah penangkapan (fishing ground); 3) Penurunan bubu kubah (setting); 4) Perendaman bubu kubah (soaking) dan 5) Pengangkatan bubu kubah (hauling).

\section{PENUTUP}

Pengabdian kepada masyarakat penerapan teknologi penangkapan rajungan (Portunus pelagicus spp.) dengan bubu kubah bagi nelayan Kecamatan Johan Pahlawan Kabupaten Aceh Barat telah berjalan sesuai yang diharapkan dan harapannya dapat memberikan manfaat bagi mitra pengabdian masyarakat dalam keberlanjutan usaha penangkapan rajungan pada kelompok nelayan mitra. Pengabdian yang kami lakukan ini telah melaksanakan seluruh kegiatan yang telah direncanakan yang meliputi edukasi, pelatihan pembuatan dan pegoperasian perangkap (traps) bubu kubah.

\section{UCAPAN TERIMA KASIH}

Ucapan terima kasih disampaikan kepada:

1) Kementerian Riset, Teknologi dan Pendidikan Tinggi yang telah memberikan pendanaan melalui hibah pengabdian kepada masyarakat skim Program Kemitraan Masyarakat (PKM).

2) Nelayan perintis bubu kubah di Gampong Ujong Baroh Kecamatan Johan Pahlawan Kabupaten Aceh Barat sebagai pihak mitra.

3) Aparatur Gampong Ujong Baroh Kecamatan Johan Pahlawan Kabupaten Aceh Barat yang telah memberikan ijin dan memfasilitasi kegiatan ini.

4) Bapak Muhammad Agam Tahir, S.Pi., M.Si (Dosen Prodi Perikanan Fakultas Perikanan dan Ilmu Kelautan Universitas Teuku Umar) dan Sdr. Sayid Geubri Alfarisi, S.IK (tenaga lapang kegiatan PPM) serta Abdul Karim (mahasiswa Prodi Perikanan FPIK UTU) yang telah banyak membantu kegiatan ini.

\section{DAFTAR PUSTAKA}

Zarochman. 2015. Inovasi teknologi penangkapan rajungan ramah lingkungan dengan bubu kubah. Prosiding Lokakarya Nasional Kemaritiman. 11 Juni 2015, Meulaboh, Indonesia. Hal. 39-52.

Menteri Kelautan dan Perikanan. 2015. Peraturan Menteri Kelautan dan Perikanan Republik Indonesia Nomor 2/PERMEN-KP/2015 tentang larangan penggunaan alat penangkapan ikan pukat hela (trawls) dan pukat tarik (seine nets) di wilayah pengelolaan perikanan negara Republik Indonesia. Jakarta: Kementerian Kelautan dan Perikanan 


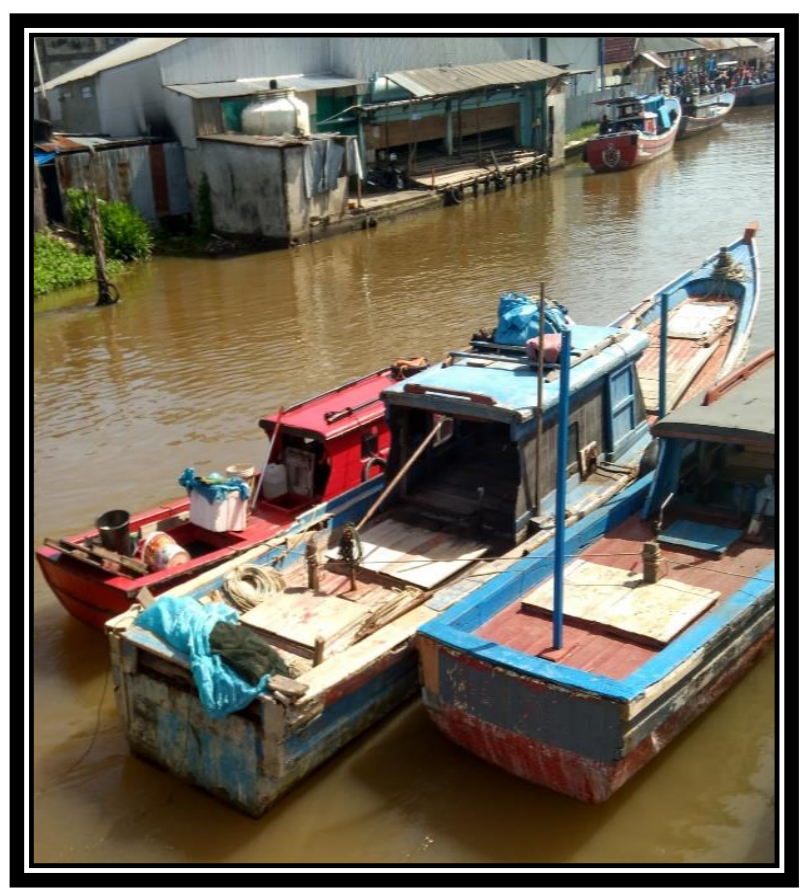

Gambar 1. Kondisi kapal penangkapan ikan menggunakan alat tangkap mini trawl.

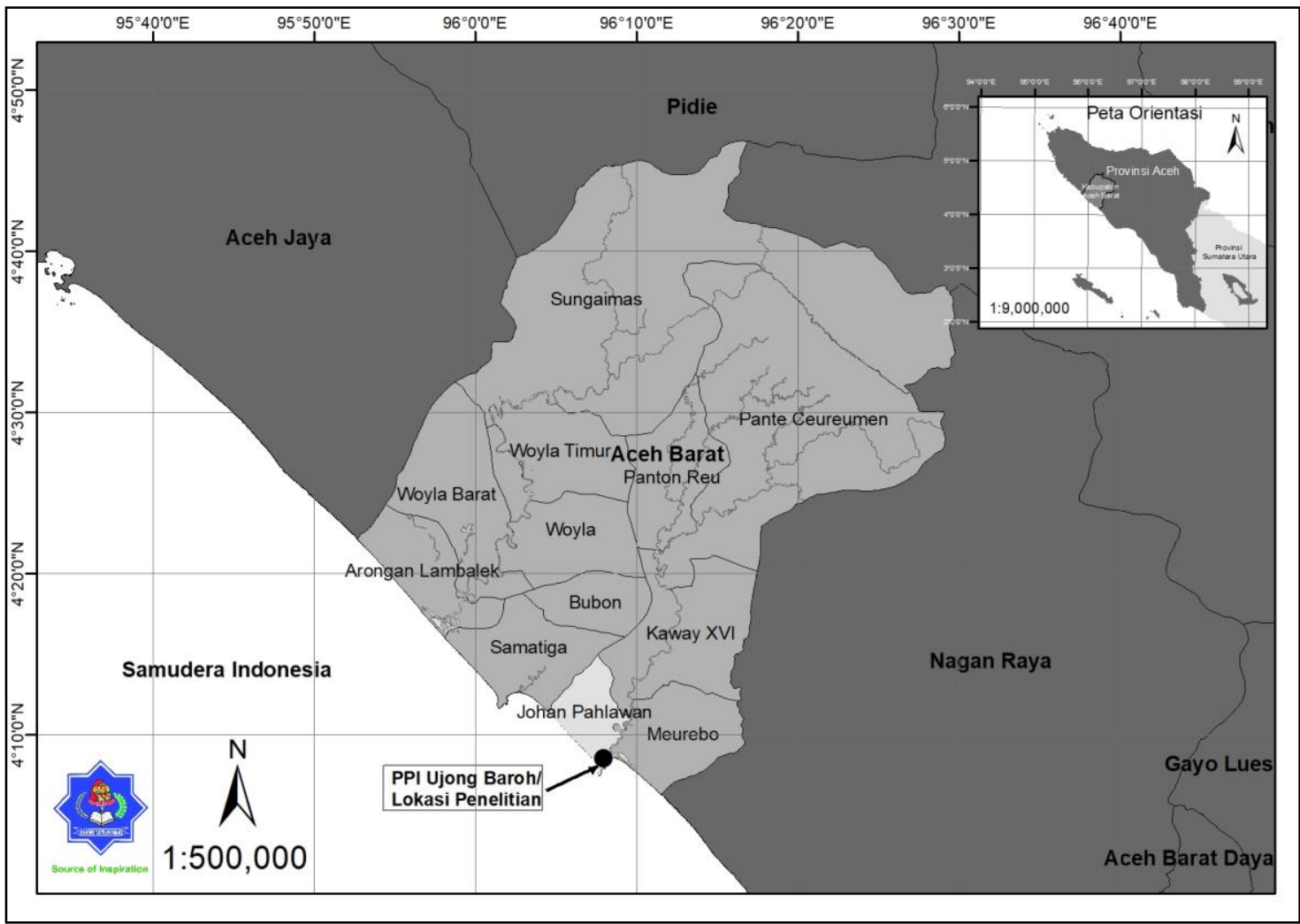

Gambar 2. Peta lokasi mitra nelayan perintis bubu kubah 


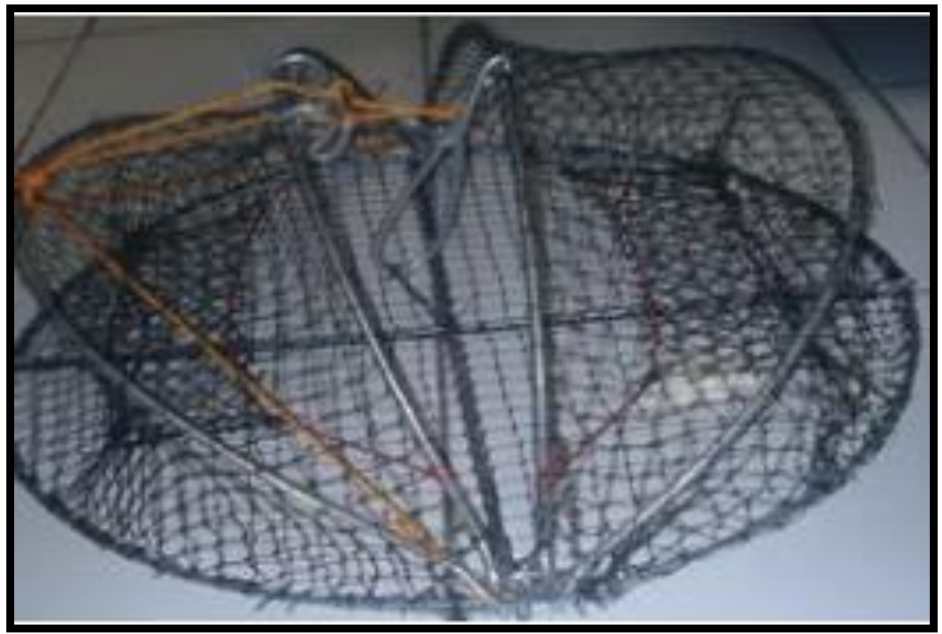

Gambar 3. Kontruksi bubu kubah.

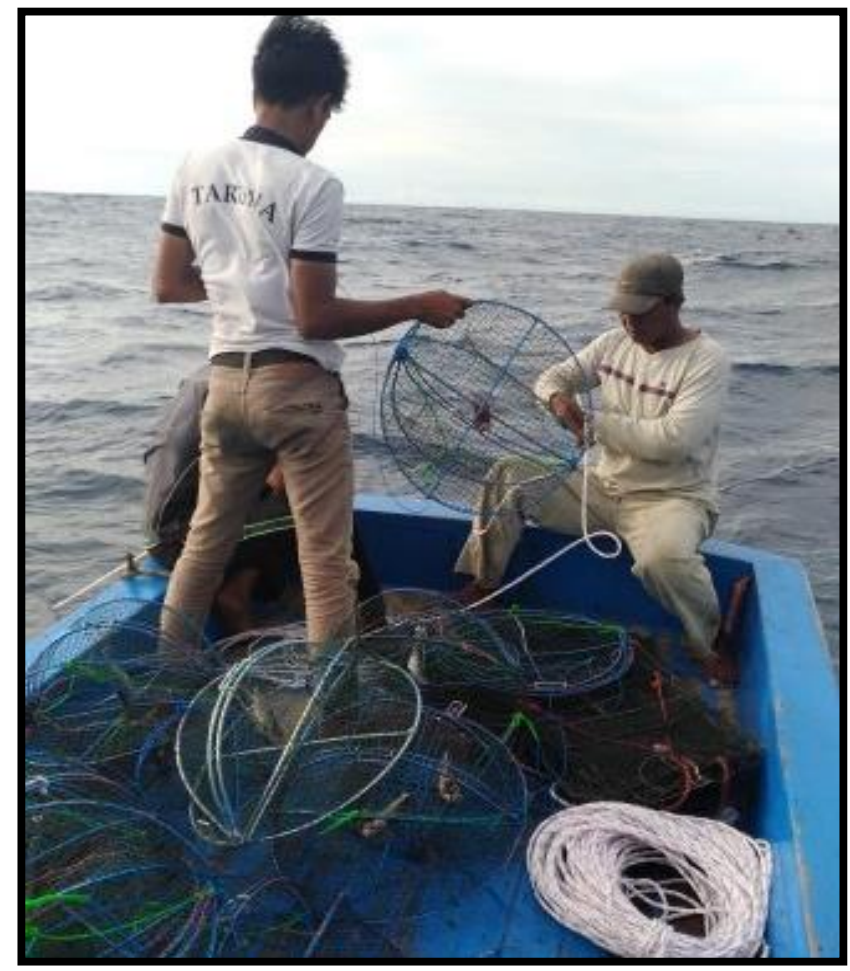

Gambar 3. Pengoperasian bubu kubah bersama nelaya mitra 
Tabel 1. Bahan bubu kubah

\begin{tabular}{|c|c|c|c|}
\hline No & Uraian & Jenis bahan & Ukuran \\
\hline \multirow{11}{*}{1} & \multicolumn{3}{|c|}{ Kerangka bubu } \\
\hline & - Bawah: & & \\
\hline & Lingkara & & $\theta 0.6$ \\
\hline & $n \quad \theta 48$ & Beton eser & $\mathrm{cm}$ \\
\hline & $\mathrm{cm}$ & & \\
\hline & - Atas: & & \\
\hline & Lingkara & Beton ecer & $\theta \quad 0.6$ \\
\hline & $\begin{array}{lll}n & \theta & 14\end{array}$ & Beton eser & \\
\hline & $\mathrm{cm}$ & & \\
\hline & - Samping: & & \\
\hline & $\begin{array}{l}\text { lengkung } \\
\text { an }\end{array}$ & Beton eser & $\begin{array}{ll}\Theta & 0.6 \\
\mathrm{~cm} & \end{array}$ \\
\hline \multirow[t]{2}{*}{2} & Badan & Webbi & D 6; \\
\hline & bubu & vienouing & \\
\hline \multirow[t]{2}{*}{3} & Mulut bubu & Beton eser & $\theta \quad 0.6$ \\
\hline & & & $\mathrm{cm}$ \\
\hline 4 & Tali guci & PE & $\theta 3 \mathrm{~cm}$ \\
\hline 5 & Tali cabang & PE & $\theta 4 \mathrm{~cm}$ \\
\hline 6 & Snap & Stainlessteel & \\
\hline 7 & Pemberat & $\mathrm{Pb}$ & $\begin{array}{l}\text { Berat } 1 \\
\mathrm{~kg}\end{array}$ \\
\hline 8 & $\begin{array}{l}\text { Tempat } \\
\text { umpan }\end{array}$ & Beton eser & $\begin{array}{ll}\theta & 0.4\end{array}$ \\
\hline 9 & & & \\
\hline & pelampung & PE & $\begin{array}{l}\Theta \\
\mathrm{mm}\end{array}$ \\
\hline
\end{tabular}

